\title{
Correction to: Electricity demand in industrial and service sectors in Taiwan
}

\author{
Yu-Wen Su
}

Published online: 21 April 2018

(C) Springer Science+Business Media B.V., part of Springer Nature 2018

\section{Correction to: Energy Efficiency}

https://doi.org/10.1007/s12053-018-9615-y

In table 1 columns 10 and 16 , the value of the average price was updated. In Fig. 2b, some parts of the line graph were removed by mistake during production.

The original publication was updated.

The online version of the original article can be found at https://doi. org/10.1007/s12053-018-9615-y

Y.-W. Su $(\bowtie)$

Industrial Economics and Knowledge Center, Industrial

Technology Research Institute, Rm. 102, Bldg. 10, 195, Sec. 4,

Chung-Hsing Rd., Hsinchu, Taiwan 31040

e-mail: sophieywsu@gmail.com 